\title{
ADAPTASI DAN TRANSFORMASI LAGU ADAT DALAM LITURGI GEREJA KATOLIK DI MANGGARAI FLORES
}

\section{ADAPTATION AND TRANSFORMATION OF TRADITIONAL SONGS TOWARDS CATHOLIC LITURGICAL HYMNS IN MANGGARAI FLORES}

\author{
Yohanes S. Lon dan Fransiska Widyawati* \\ Universitas Katolik Indonesia Santu Paulus Ruteng \\ Emal:yohservatiusboylon@gmail.com \\ Submitted: 21-04-2019; Revised: 19-03-2020; Accepted: 17-05-2020
}

\begin{abstract}
Manggarai, a community in Flores, Eastern Indonesia is known for its rich culture of folk songs with unique rhythm and lyrics. There are various types of folk songs for different purposes such as traditional chants, harvest celebrations, lamentation of the dead, war anthems, children songs, and other profane functions. When European missionaries started Catholic evangelization in Manggarai in the beginning of the $20^{\text {th }}$ century, many of these folk songs were prohibited due to their use in rituals deemed idolatry. However, some missionaries saw the potential of folk songs for evangelization and empowered local artists to arrange Catholic liturgical songs based on these traditional songs. Eventually, many folk songs were adapted and transformed into Catholic hymns. This paper explores this irony through socio-historical research to understand the relationship dynamics between the Catholic Church and the Manggaraian culture. This research has discovered that there is a dialectical encounter between Catholicism and the Manggaraian culture which has shaped a unique identity of the Catholic Church in Manggarai.
\end{abstract}

Keywords: Catholic; Folk-songs; Identity; Inculturation; Manggarai.

\begin{abstract}
ABSTRAK
Orang Manggarai di Flores, Indonesia memiliki kekayaan seni lokal yang unik. Seni musik, suara, dan tarian dipakai untuk aneka kepentingan berbeda di dalam ritual adat dan kseharian hidup masyarakat. Ketika misionaris Eropa mulai menyebarkan agama Katolik di wilayah ini pada awal abad 20, banyak seni dan ritual adat dilarang karena dianggap sebagai penyembahan berhala. Akan tetapi, ada kelompok misionaris melihatnya secara berbeda. Mereka melihat bahwa seni lokal sangat potensial untuk menghidupkan liturgi Katolik yang olehnya agama ini bisa mendapat tempat di hati masyarakat. Artikel ini mengeksplorasi proses adaptasi dan transformasi lagu adat Manggarai ke dalam liturgi Gereja Katolik. Dengan ini, paper ini akan menemukan model perjumpaan agama Katolik dan budaya Manggarai. Penelitian ini menemukan bahwa perjumpaan budaya lokal dan agama mondial di Manggarai telah membentuk identitas unik orang Katolik Manggarai. Proses ini ditandai oleh dialektika yang mutualis namun juga konfliktual dan ironis.
\end{abstract}

Kata Kunci: Identitas; Inkulturasi; Katolik; Lagu Adat; Manggarai.

*Corresponding author: fwidyawati10@gmail.com

Copyright@ 2020 THE AUTHOR (S). This article is distributed under a Creative Commons Attribution-Share Alike 4.0 International license. Jurnal Kawistara is published by the Graduate School of Universitas Gadjah Mada. 


\section{PENGANTAR}

Studi terkini tentang perjumpaan etnis, musik lokal, dan agama di Indonesia menarik perhatian banyak peneliti. Harnis and Rasmussen (2012) yang melakukan kajian atas Islam dan musik di aneka wilayah di Indonesia memperlihatkan bahwa agama Islam telah menjadi sumber inspirasi aneka ekspresi musik lokal dan populer pada aneka suku dan kebudayaan di seluruh Indonesia. Sebaliknya pula, musik juga memberi warna bagi pembentukan konteks dan identitas baru agama Islam dan budaya lokal. Di dalam perjumpaan itu, ada pergulatan identitas, ketegangan dan perubahan, baik bagi agama, etnis maupun musik itu sendiri.

Harnish (2006, 2014) yang melakukan kajian atas festival Lingstar di Lombok memperlihatkan seni lokal adalah jalan menghubungkan antara aneka aktor atau agen. Ia memperjumpakan leluhur di masa lalu dengan masyarakat di masa kini; ia menjadi media perjumpaan aneka agama (Islam, Hindu) dan juga antaretnis di Lombok (dan Bali). Seni terus menerus membentuk wajah agamaagama dan relasi etnis. Identitas Hindu dan Islam di Lombok dan Bali adalah sebagian dari hasil dari dinamika seni dan kontestasi sosio politik. Studi Rahim dan Christianto (2019) mengenai tradisi Nyongkolan di Lombok juga menegaskan bahwa selalu ada negosiasi antara budaya dan agama.

Kajian mengenai seni dan agama Kristen/Katolik di Indonesia juga memperlihatkan trend yang sama. Kontekstualisasi gereja-gereja Kristen di Indonesia lainnya juga terjadi antara lain dengan memanfaatkan seni dan budaya lokal di dalam liturgi. Marzanna Polawska (2011) melihat bahwa musik lokal yang dipakai dalam Gereja-gereja Indonesia adalah hasil dari perjalanan sejarah yang panjang dari proses "inkulturasi". Inkulturasi juga merupakan hasil dari produk kreativitas manusia dan keinginan untuk membuat musik dekat dengan hati rakyat. Studi Polawska mengenai inkulturasi di dalam Gereja Protestan Jawa, menemukan bahwa "inculturation is often marked by struggle and contestation" karena ada klaim dan perdebatan apakah suatu seni itu cocok atau tidak untuk kepentingan liturgis Gereja. Di dalam semuanya wajah Gereja dan budaya lokal menjadi semakin dinamis.

Studi-studi ini memperlihatkan bahwa seni dan kebudayaan lokal telah mengambil peran penting dalam proses pembentukan identitas budaya lokal, agama (impor) dan bagaimana proses perjumpaan keduanya mengkonstruksikan identitas baru (Bdk. Chistantyawati, Walensa dan Juraman, 2018). Perjumpaan itu sifatnya dinamis, harmonis namun juga konfliktual. Penelitian ini ingin masuk di dalam arus diskusi ini. Fokusnya pada adaptasi dan transformasi lagu dan musik adat Manggarai di Flores ke dalam liturgi Gereja Katolik. Flores dikenal sebagai Pulau Katolik satu-satunya di Indonesia. Gereja Manggarai di Flores memiliki sejarah dan identitas yang khas dan unik hasil perjumpaan antara budaya/keyakinan lokal dengan misi agama dan pembangunan misionaris Eropa (Widyawati dan Lon, 2019).

Dengan menggunakan pendekatan sosio historis, paper ini mendiskusikan proses adaptasi dan transformasi lagu-lagu adat di Flores Barat ke dalam Gereja Katolik sejak awal abad 20 hingga dewasa ini. Pioner dari usaha ini adalah misionaris Eropa yang bekerja sama dengan seniman lokal. Ironisnya, banyak lagu yang awalnya dianggap sebagai berhala ataupun sesuatu yang terlalu profan justru digubah menjadi lagu "suci". Lagu yang semula memiliki fungsi kultural berbeda diubah menjadi lagu-lagu sakral agar liturgi gereja dialami sebagai yang indigenous artistic expression. Ironi lainnya ialah, proses ini justru melemah ketika misionaris asing telah tiada dan pejabat Gereja justru berasal dari masyarakat setempat sendiri. Bagaimanapun proses inkulturasi ini membuat agama Katolik menjadi bagian dari kebudayaan dan identitas masyarakat setempat.

\section{Sepintas Mengenai Gereja Katolik di Manggarai}

Meskipun kekatolikan di Pulau Flores bagian timur sudah dimulai abad 16 oleh misionaris Eropa, sampai dengan awal abad 
20, mereka tidak tertarik menyebarkan agama ini sampai ke Manggarai, wilayah barat pulau ini. Ada beberapa alasan mereka tidak melakukan ekspansi agama ke wilayah barat, yaitu jumlah misionaris terbatas, kondisi alam yang sangat sulit dan ketakutan menghadapi orang Islam. Sejak abad 16 sampai 19, orang Bima dan Gowa secara bergantian menguasai wilayah ini. Kedua kesultanan ini memiliki peran penting dalam penyebaran Islam di wilayah timur Indonesia. Meskipun tujuan kedatangan mereka ke Manggarai lebih untuk berdagang dan mengeksploitasi kekayaan lokal, dan bukannya menyebarkan agama, tetapi identitas Islam mereka membuat gentar para misionaris (Steenbrink, 2013; Widyawati, 2012; Lon dan Widyawati, 2019). Apalagi studistudi memperlihatkan bahwa persaiangan dagang dan perebutan wilayah di nusantara pada masa itu, tidak terlepas dari persaingan agama. Demikianlah konteks ini membuat misionaris tidak berani ke Manggarai.

Walaupun, dalam realita, perkembangan Islam sangat terbatas pada wilayah pantai saja dan mereka adalah imigran asal Bima dan Gowa. Penduduk asli yang memiliki adat yang kuat dan di dalam adat itu babi dan daging babi sangat penting, maka konversi ke Islam adalah hal yang sangat sulit untuk dilakukan. Perkembangan Islam juga sesungguhnya lambat karena kebijakan Sultan Abdul Hamid Syah, yang melarang orang Bugis, Makasar, dan Bima untuk tetap tinggal di pantai dan menjauhi penduduk lokal karena dapat membahayakan iman mereka (Coolhas, 1942).

Pada tahun 1907, pasukan Belanda secara resmi menduduki Manggarai. Pejabat Belanda melihat bahwa jumlah penduduk Manggarai yang banyak dan wilayah yang luas sangatlah potensial bagi masa depan agama Katolik. Maka mereka mendesak pejabat Gereja Katolik di Batavia dan di wilayah timur Flores untuk mengirim misionaris ke Flores Barat. Akhirnya dengan kerja sama Gereja Katolik dan dukungan kuat penjajah Belanda, misionaris dikirim ke wilayah ini secara resmi tahun 1915.

Kedua pihak ini juga bekerja keras untuk melemahkan pengaruh Bima atas daerah dan penduduk lokal. Penjajah memutuskan untuk menjadikan Manggarai sebagai daerah swapraja (waarnemende bestuurder van landschap Manggarai). Pada tahun 1923, pemerintah mengangkat tokoh adat lokal dari Todo sebagai "the first king of the Zelfsbestuur (swapraja) government" atas seluruh Manggarai (Toda, 1999: 313-315, 327). Todo adalah kampung adat yang membawahi kampung-kampung lainnya di Manggarai. Dengan ini Bima secara resmi tidak lagi memiliki kekuasaan di wilayah ini.

Dengan berakhirnya kekuasaan Bima (Islam) dan penguasaan Belanda atas otoritas lokal (Todo), maka Manggarai dengan mudah dikuasai. Hal ini sangat menguntungkan misionaris Katolik. Kerja sama keduanya melancarkan usaha untuk mengkatolikkan wilayah ini lebih mudah. Hal ini semakin menguat dengan diangkatnya alumni sekolah Katolik, tokoh pemuda dari Todo yang bernama Alexander Baroek, sebagai "king of Manggarai" pada tahun 1931. Ini adalah strategi jitu karena seperti kata Steenbrink (2007: 81),

"He could not yet show strong authority in front of other local rulers and even less against the Catholic clergy, who took charge for him during his education".

Gereja Katolik akhirnya dengan mudah menyebarkan agama di wilayah ini. Hasilnya, hanya dalam kurun waktu 20an tahun saja, sejak tahun 1930an, hampir semua orang Manggarai telah beralih dari agama asli ke agama Katolik. Usaha ini menjadikan target misionaris menjadikan Flores sebagai "Pulau Katolik" tercapai. Menurut Sensus Penduduk tahun 2010, jumlah orang Katolik mencapai 90\% di Flores, termasuk di Manggarai. Manggarai sendiri menjadi satu keuskupan dengan jumlah umat Katolik terbanyak di Indonesia dan bahkan jumlah imam dan biarawati terbanyak pula di negara ini.

Selain dukungan politik, keberhasilan misionaris juga karena strategi mereka yang tidak hanya memusatkan diri pada misi keagamaan belaka, tetapi turut serta dalam pembangunan masyarakat. Misionaris membuka sekolah, klinik kesehatan, pasar, koperasi. Mereka mengembangkan irigasi, model pertanian, perumahan, dan tata sosial yang 
lebih modern (Erb dan Widyawati, 2018). Salah satu cara Gereja menarik perhatian dan mengambil hati orang Manggarai adalah dengan mengkontekstualisasikan Gereja ke dalam budaya orang Manggarai melalui usaha yang disebut inkulturasi, termasuk dengan penggunaan seni lokal dengan tradisi dan liturgi gereja inilah yang menjadi fokus paper ini.

\section{Musik dan Lagu Manggarai Sakral dan Profan}

Studi yang dilakukan Rappoport (2015) memperlihatkan bahwa wilayah Indonesia timur kaya dengan keragaman musik dan lagu. Kekayaan ini adalah hasil dari proses historis yang terus berlanjut. Kunst (Bdk. Yampolsky, 2015)) berpendapat bahwa musik di Flores sangat unik dibandingkan dengan musik di wilayah nusantara lainnya. Menurut hipotesanya, hal ini terjadi karena adanya "Pontian migration" dari Laut Hitam ke Asia Tenggara pada abad 19S.M, maka tak heran jika, khususnya di Flores bagian timur, ada gaya Balkan. Ada juga pendapat lain yang melihat bahwa di beberapa wilayah Flores bagian tengah ada kemiripan dengan musik vokal di Eropa Tenggara dan Osenia (Messner, 1981). Salah satu kekhasan musik dan lagu di Flores adalah nyanyian di dalam kelompok. Ada yang bersifat antiphony song yaitu seni yang mengkolaborasikan tarian, lagu dan ritual. Penyanyi terdiri dari kelompok perempuan dan laki-laki yang menyanyikan secara bergantian. Namun lagu yang dinyanyikan duet dan tunggal juga ada.

Seperti halnya komunitas lain di Flores, musik dan seni dalam tradisi orang Manggarai berkaitan erat dengan kosmologi kehidupan mereka yang sakral maupun profan. Sebagai komunitas yang agrikultural, ritual-ritual orang Manggarai selalu dikaitkan dengan pesta kebun dan musim. Mereka yakin bahwa hidup mereka selalu dinaungi oleh roh-roh yang ada di rumah, kampung, kebun, tanah, mata air dan aspek lainnya. Cara berkomunikasi dengan mereka adalah melalui ritual yang mempersembahkan kurban dalam bentuk hewan. Di dalam ritual itu leluhur diundang untuk datang dan komunitas merayakan kehadiran mereka. Perayaan itu ditandai pula dengan musik, tarian dan nyanyian.

Orang Manggarai mengenal beberapa jenis kesenian lokal tua: seni suara (déré), seni musik dan seni tari (saé) seperti: mbata, sanda, danding/ déndé, ronda, renggas, landu, nénggo, osang, déré seperti déré adak (beo, kaba, lingko, naring, penti) déré du caci, déré ceha kila, déré gampo latung, dérédu tombo turuk, dan lain-lain. Seni musik orang Manggarai terbatas pada gong, tebong, tambor, lama, mbetung, sundingdan gendang. Jenis tarian (saé) yang dikenal antara lain: saé kaba (tarian kerbau), saé tiba meka (tarian menyambut tamu), pemaka (tarian mengusir roh jahat yang bisa mengganggu kegiatan tertentu), saé jarang (tarian kuda), saé randang beo (tarian meriah menganggungkan kampung), saé randang mosé (tarian merayakan kehidupan), dan ndundu-ndaké.

Beberapa jenis tarian, musik dan lagu hanya bisa dimainkan pada waktu, tempat dan kesempatan khusus karena sifatnya yang sakral dan berhubungan dengan ritual khusus. Sebagai contoh, mbata dan sanda du penti saat pesta syukur panen, hanya boleh dilakukan di rumah ada (mbaru gendang) dan waktunya hanya pada malam hari. Syair dan lirik lagu biasanya juga bersifat khusus, misalnya berisi pujian dan pengagungan leluhur, pengisahan sejarah kampung, filosofi kehidupan, ratapan kesedihan atas kematian, bencana dan duka, pesan perdamaian, nasihat khusus bagi keluarga dan generasi muda, dan lain-lain.

Syair lagu ada yang sifatnya menetap, artinya lagu yang sama dinyanyikan turun temurun, ada pula yang diciptakan baru terus menerus oleh seniman lokal, ada pula yang aksidental yakni syairnya diciptakan secara mendadak pada saat upacara berlangsung. Peralatan gong dan gendang yang digunakan pada pertunjukkan ini juga khusus karena memakai alat musik yang ada di rumah adat, yang tidak bisa dimainkan pada waktu sembarangan dan tidak bisa pula dibawa ke luar rumah adat tanpa upacara khusus. Penyimpangan aturan adat ini diyakini masyarakat bisa menyebabkan itang agu nangki yaitu kutukan, bencana dan kemalangan yang menimpa warga kampung dan keturunannya. Dalam studi sosiologi dan antropologi klasik hal 
ini berhubungan erat dengan konsep mengenai yang sakral, yang dibedakan dari yang profan.

Lagu, tarian dan musik profan jenis dan genrenya bisa sama dengan lagu yang sakral hanya berbeda pada syair yang lebih umum dan waktu kapan ditampilkan atau dimainkan yang bebas. Tujuannya juga bermacammacam, misalnya sebagai hiburan, pelepas kesedihan, ungkapan cinta, sindirian, olokolokan, meramaikan suatu kegiatan seperti saat berkebun, memanen, mengumpulkan hasil, mencari kayu, dan aneka tujuan lainnya seluas irama kehidupan masyarakat. Lagu, musik dan tarian seperti ini tidak terikat pada kaidah khusus, bisa dilantunkan kapan saja, dimana saja dan oleh siapa saja.

Kendatipun telah memeluk agama Katolik, warga masih sering melaksanakan ritual yang berisi keyakinan terhadap roh. Orang Manggarai memiliki keyakinan berbentuk animisme sebagai petani. Tanah dan kosmologinya dalam ungkapan Allerton (2009: 271) sebagai "a 'lived environment', one constituted and animated by kinship connections, ancestral journeys, and potent spiritual energies". Oleh karena itu, ritual dan pesta adat melekat erat dalam keseluruhan hidup orang Manggarai, maka kesenian lama juga masih dipakai pada saat-saat khusus. Hal yang sama juga ditemukan di wilayah lain, sebagaimana misalnya studi yang dilakukan Setyari, Bendensa, Saskara (2019).

Akan tetapi, seiring dengan perkembangan zaman, musik, lagu dan tarian tradisional mulai berubah baik bentuk, ragam, fungsi dan pemaknaan. Sejak tahun 1960an, lagu pop Manggarai mulai dikenal luas. Bahkan beberapa dekade lalu, musik rap dan hiphop Manggarai juga dikembangkan oleh generasi muda. Demikian pula dengan seni tari, tarian-tarian lama/asli biasanya hanya dikenal dan ditampilkan saat ritual tertentu saja, pada aneka acara lainnya, tarian modifikasi lebih populer dan diminati oleh masyarakat khususnya generasi tua.

\section{Penerjemahan Lagu Adat sebagai Adaptasi Awal}

Ketika misionaris Katolik datang ke Manggarai awal abad 20, bahasa resmi liturgi
Gereja yang dipakai adalah bahasa Latin: semua doa dan lagu dalam ibadah menggunakan bahasa Latin. Sentralisasi penggunaan bahasa Latin untuk semua ritus Gereja Katolik di seluruh dunia merupakan hasil dari perjalanan sejarah yang panjang peradaban Eropa dan Byzantium sejak abad pertengahan. Liturgi Latin lahir bukan sekadar dari kebutuhan ibadah tetapi juga merupakan salah satu cara untuk melanggengkan kekuasaan paus, menciptakan sentralisasi di dalam Gereja Katolik di masa itu (Romano, 2014). Konsekuensinya, gereja-gereja yang tidak memiliki dan tidak terikat dengan tradisi Latin terpaksa harus tunduk dan mengikuti aturan Roma ini.Hal ini menyebabkan liturgi ekaristi menjadi hal asing, tidak dinamis dan kaku.

Hal ini juga diperkuat oleh aliran teologis yang kurang ramah terhadap kebudayaan lokal, dimana tradisi dan budaya non Kristiani dipandang rendah dan bahkan sebagai penghalang keselamatan. Kebudayaan lokal disamakan dengan penyembahan berhala. Budaya non Kristiani dianggap inferior dan bahkan melawan Yesus Kristus, agama dan Gereja. Pemahaman ini cukup kuat dalam aliran-aliran teologi sebelum Konsili Vatikan II yang sifatnya ekslusif dimana kehadiran Kristus dan Gereja dianggap sebagai kematian bagi peradaban berhala sebagaimana pandangan teolog seperti Tertullian, Leo Tolstoy, dan lain-lain. Kesetiaan kepada Kristus dan agama Kristiani bagi mereka sama dengan penolakan pada kebudayaan setempat. Niebuhr, seorang teolog Kristiani yang dengan keras menentang pemikiran yang mengganggap bahwa "Christ agains culture" (Bdk. Niebuhr, 2001).

Walaupun bahasa Latin menjadi bahasa resmi liturgi Gereja, bahasa ini nyatanya adalah bahasa yang "mati" karena tidak dipakai sebagai bahasa percakapan harian para misionaris. Misionaris Eropa menggunakan bahasa Melayu,yang umumnya mereka pelajari sebelum mereka bertugas, untuk berkomunikasi dan memperkenalkan agama kepada masyarakat lokal. Akan tetapi, pada masa itu, hanya sebagian kecil saja orang Manggarai yang bisa berbahasa Melayu. Bahasa Manggarai adalah bahasa yang paling dominan. Untuk itu, komunikasi dan bahasa 
merupakan tantangan khusus bagi karya penyebaran agama di daerah yang masih sangat terkebelakang dan asli pada masa itu.

Pada tahun 1920an, misionaris mengumpulkan sejumlah kecil umat dan mulai melakukan ibadah dengan bahasa Latin namun kotbah singkat dalam bahasa Indonesia sepatah-patah. Umat mengalami kesulitan untuk memahami. Oleh karena itu, pewartaan seakan tidak tepat sasaran dan komunikasi dalam arti sesungguhnya tidak terjadi. Umat menjadi penonton di dalam ibadah. Secara khusus bagi komunitas orang Manggarai yang ritualnya bagaikan festival, penuh keakraban, hidup dan tidak kaku, ibadah Gereja Katolik benar-benar sesuatu yang aneh.

Beberapa misionaris menyadari hal ini. Mereka mulai belajar bahasa Manggarai dan menerjemahkan beberapa doa. Seorang misionaris Belanda menulis bahwa untuk pertama kalinya sesudah misa yang dibawakan dalam bahasa Latin, ia melantunkan doa tambahan dalam bahasa Manggarai pada 18 Mei 1922 dan sebulan kemudian ia berkotbah singkat di dalam misa juga dengan bahasa Manggarai (Jehandut, 2012: 32).

Usaha yang lebih sistematis mengumpulkan bahasa Manggarai untuk kepentingan misi dan kepentingan lebih luas dilakukan oleh P.A. Burger tahun 1949. Ia melakukan studi bahasa yang cukup intens namun sayangnya ia cepat meninggal. Hasil karyanya dipublikasikan oleh gurunya yaitu Prof. J. Gonda (Verheijen, 1970: i-xii). Studi bahasa Manggarai yang paling luar biasa dan intens dilakukan oleh J.A.J. Verheijen.Misionaris Katolik asal Belanda ini memiliki latar belakang antropologi. Ia mulai mengumpulkan kata, istilah, cerita, pemikiran, aktivitas dan aspek-aspek budaya orang Manggarai sejak tahun 1937. Hasilnya ia dapat mempublikasikan dua kamus yang diterbitkan penerbit kenamaan di Belanda tahun 1967 dan 1970. Karya-karya ini menjadi jalan bagi Gereja Katolik untuk membawa bahasa dan keyakinan lokal ke dalam liturgi Gereja.

Setelah umat mulai mengenal doa dalam bahasa Manggarai, misionaris merasa perlu mengadaptasi lagu dalam bahasa Manggarai untuk perayaan ekaristi resmi di Gereja dan ibadah komunitas. Idenya agar liturgi Gereja tidak menjadi asing bagi umat. Upaya awal yang dilakukan adalah menerjemahkan lagu Latin ke dalam bahasa Manggarai. Pada tahun 1922, dua lagu berjudul "Mengasih Maria" dan "Asperges" yang berasal dari bahasa Latin diterjemahkan ke dalam bahasa Manggarai, dengan judul Mai Momang Maria dan Asperges. Lagu pertama adalah pujian kepada Maria, lagu yang biasanya dinyanyikan sebelum atau setelah perayaan ekaristi atau saat devosi kepada Maria di luar perayaan ekaristi. Lagu kedua adalah lagu adalah lagu yang dinyanyikan saat perayaan ekaristi dimana imam menyiramkan air kepada umatnya sebagai lambang pembersihan.

Usaha penerjemahan kedua lagu awal ini mencuri perhatian dan simpatik umat. Olehnya, usaha penerjemahan lagu-lagu Latin Gerejani terus dilakukan oleh misionaris bersama dengan guru agama dan tokoh umat setempat (Jehandut, 2012: 4). Sampai dengan tahun 1954, di bawah kordinasi misionaris Willem van Bekkum, seniman lokal menerjemahkan 77 lagu, 84 lagu pada tahun 1963 dan 89 lagu tahun 1973.

\section{Transformasi Lagu Adat}

Sejak tahun 1930an, sembari tetap menerjemahkan lagu-lagu Latin ke dalam bahasa Manggarai, misionaris memberanikan seniman lokal untuk menciptakan lagu berbasis lagu adat menjadi lagu misa dan liturgi lainnya(Verheijen, 1938: 1; Jenadut, 2002: 46). Hasilnya, lagu pertama "diciptakan" tahun 1936 oleh seorang guru sekolah dasar, P. Manti, menciptakan lagu "Doing koé Ga" (Sadarlah) dan "Moriga Kristus" (Kristus Tuhan). Yang disebut "menciptakan" sebenarnya ialah sang penulis mengganti syair dan konteks lagu asli menjadi syair dan konteks baru. Nada, irama dan jenis musiknya tetap sama hanya kata-kata dan penggunaan yang berbeda. Ini adalah awal transformasi lagu adat ke dalam lagu Gereja.

Salah satu versi asli lagu pertama, Doing koé $\mathrm{Ga}$, adalah lagu gembira yang mengisahkan kunjungan ke kampung halaman. Ketika dipakai dalam liturgi Gereja isinya diubah menjadi lagu pertobatan/penyesalan. Bandingkan adaptasi lagu profan dan isi syair yang bertransformasi di bawah. 


\section{Lagu Adat}

Di'a Bail Na

Di'a bail na, di'a bail no'o mai gé ...

Mai léjong béo ké, mai lambu mbaru

Di'a bail no'o mai gé ...

Caik aku cé'é gé tiba le lawa lima gantang...

Lawé lénggong a...

Aé lawé lénggong a é ...

Woko lélo, di'a bailno'o mai gé

Terjemahan Bebas

Sangatlah indah, sangatlah indah

Marilah dan datanglah

Tengoklah kampungmu,

Mari sukacitakan rumah adat

Sangatlah indah, sangatlah indah

Saya datang, dan marilah kita bernyanyi gembira

Sedangkan lagu kedua (Moriga Kristus), menurut Jehandut (2012: 47), aslinya adalah lagu perang, lagu yang dipakai untuk menyemangati prajurit untuk bertempur. Ketika dipakai dalam liturgi Gereja ia diubah menjadi lagu mengenai Kristus yang menderita (Jehandut, 2012: 47). Sayang sekali penelitian ini tidak berhasil menemukan versi lagu perang itu. Salah satu responden kami yang sangat mengenal lagu adat justru mengatakan bahwa

\section{Lagu Asli/Lokal}

O Nai Go

O nai go o o

Némba tana

Ndéréng tana lé

Lingot para kilo

Élang élang a

Élang nai go

O todo lamung go

Pra mbaru ga

Todo lamung para mbaru ga

Nai go

Nai go o

Wéléng wéléng nai gé

Terjemahan Bebas

O hatiku

O Hatiku

Tanah menjadi kering

Tanah memerah

Rumah menjadi hampa

Oh hatiku

\section{Lagu Liturgi}

Doing koé ga

Doing koé ga, doing koé ga,

o mosé dé...

O é mosé dokong lino hoo,

doing koé o mosé dé.

Ai makit lé mosé léwé,

cé cé Déwa mésé,

doing koé o mosé dé.

Terjemahan Bebas

Sadarlah, sadarlah,

Sadarlah akan hidup ini

Hidup fana di dunia ini

Sadarlah

Karena hidup tak abadi

Dewa akan datang

Sadarlah akan hidupmu

sejauh yang ia kenal, lagu itu bukan berasal dari lagu perang, melainkan lagu profan. Syairnya berkisah tentang seorang yang bersedih hari karena nasib buruk yang menimpanya. Kesedihan ini menjadi dasar untuk menyusun lagu yang juga berirama sedih, yakni lagu di masa puasa mengenang sengsara dan penderitaan Kristus. Di sini penderitaan manusia dalam lagu lokal ditransformasikan ke penderitaan Kristus. Perhatikan syair di bawah ini.

\section{Lagu Gereja}

Mori ga Kristus

Mori ga Kristus Emag i o oo

Nia amego, Mori ga

Nia amego o

Mori sambe ga

Ame go o weong weleng nai ge

Elang elang ta

Elang nai go yo

Dopo da' at no anak a

Dopo daat no anak a

Dopo daat sambe wakar a Naigo

Weong weleng nai go

Weong weleng nai ge e..

Terjemahan Bebas

Yesus Kritus Tuhanku

Dimana Bapaku, Tuhanku

Dimana Bapaku

Tuhan selamatkanlah

Bapaku hatiku sedih

Cepatlah 
Oh hatiku

Pintu rumah ditumbuhi jamur

Oh hatiku

Oh jiwaku

Sedih dan kesepian

Kedua lagu ini adalah merupakan jenis sanda, yang awalnya dinyanyikan hanya di dalam rumah adat dan pada malam hari saja. Akan tetapi, dibawa ke wilayah liturgi Katolik, maka lagu ini dinyanyikan di Gereja atau dimana saja umat berkumpul untuk ekaristi. Waktunyapun disesuaikan, tidak harus dilakukan pada malam hari.

Diterimanya dua lagu pertama ini di kalangan umat, menginsipirasiWillem van Bekkum, untuk mendorong seniman lokal mengadaptasi lagu-lagu adat lainnya menjadi lagu gereja. Dicatat bahwa sejak tahun 1937 sampai 1942, terdapat 14 lagu yang diciptakan seniman lokal: 4 lagu tahun 1937, 2 lagu tahun 1938, 4 lagu tahun 1939, 3 lagu tahun 1940 dan 1 lagu tahun 1942. Tahun 1941, lagu-lagu yang telah diciptakan oleh seniman lokal maupun hasil terjemahan lagu Latin ke dalam bahasa Manggarai dijilid dalam bentuk stensilan sederhana dan diketik dalam beberapa rangkap sehingga bisa dipakai di beberapa paroki/stasi (Jehandut, 2012:47-50).

Pada tahun 1942-1945 misionaris asal Eropa ditawan oleh tentara Jepang di Sulawesi. Tidak ada lagu Manggarai yang diciptakan pada masa ini. Baru pada tahun 1946, ketika misionaris kembali ke Manggarai, tiga lagu kembali diciptakan lagi dan dua lagu berikutnya diciptakan tahun 1949. Pada tahun 1947, kumpulan lagu-lagu ini dicetak pada percetakan Arnoldus Ende untuk pertama kalinya. Percetakan ini merupakan percetakan milik SVD, merupakan salah satu percetakan tertua di Indonesia. Buku lagu itu dinamakan Déré Serani (Nyanyian Kristiani). Déré Serani menjadi buku lagu gereja dalam bahasa daerah pertama yang pernah ada di seluruh Gereja Indonesia kala itu. Ia menjadi contoh dan pelopor bagi inkulturasi liturgi di wilayah lain di Indonesia (Prier, 2007).

Pada tahun 1953 sampai 1962, ada 49 lagu lokal baru diadaptasi dan diciptakan menjadi lagu Gereja. Ini periode dimana begitu banyak
Bersegeralah

Sedih penderitaan anakmu

Menderita demi menebus jiwa

Sedih dan dukalah hatiku

Sedih dan dukalah hatiku

lagu diciptakan. Pada tahun 1954, Déré Serani dicetak kedua kalinya dengan isi sebanyak 94 lagu yang terdiri dari 77 lagu terjemahan dan 17 lagu asli Manggarai. semua ini karena usaha keras dari Wilhelmus van Bekkum, yang sejak tahun 1961menjadi Uskup pertama di Manggarai. Ia pulalah yang mendisain "misa kaba" (misa kerbau) yakni misa yang dipadukan dengan upacara penyembelihan kerbau pada pesta syukur panen. Ia terus bergiat mendorong seniman lokal untuk mencipta sebanyak mungkin lagu. Tahun 1960, Komisi Liturgi Vikariat Ruteng mengeluarkan sebuah buku berisikan lagu-lagu hasil karya seniman lokal. Ada 52 lagu Gereja Manggarai asli hasil karya dari 24 seniman lokal. Lagu-lagu itu disatukan dalam bentuk Buku yakni Déré Serani II dan dicetak di percetakan Arnoldus Ende tahun 1960.

Pada tahun 1963 dibuat cetakan ketiga, kedua seri itu digabungkan dan ditambah lagi dengan beberapa lagu baru, sehingga terdapat 180 lagu, 96 lagu asli dan 84 lagu terjemahan. Ini adalah tahun dimana Konsili Vatikan II sedang dalam masa sidangnya. Peran Mgr. Van Bekkum sangat penting dalam Konsili di Roma itu. Ia memperlihatkan contoh bagaimana penggunaan budaya lokal dalam liturgi Gereja adalah satu hal yang harus diperhatikan Gereja universal. Penciptaan lagu dan penerjemahan lagu untuk mengisi Déré Seraniterus berlanjut hingga tahun 1973. Ketika dicetak yang keempat jumlah lagu pada buku itu sebanyak 224 lagu dengan 135 lagu asli Manggarai dan sisanya lagu terjemahan.

Seperti halnya lagu-lagu awal, lagu yang diadaptasi pada masa ini juga berasal dari lagu yang awalnya dipakai untuk kepentingan yang berbeda dari orang Manggarai. Perhatikan beberapa contoh di bawah ini. Lagu-lagu di bawah ini memiliki konteks, isi dan pesan yang sama sekali tidak berkaitan dengan pesan atau isi lagu ketika itu ditransformasikan ke dalam liturgi gereja. 


\begin{tabular}{|c|c|c|}
\hline No & Lagu Lokal & Lagu Gereja \\
\hline 1 & $\begin{array}{l}\text { Inang-Amang } \\
\text { A ... é ... go lé lé lé ... } \\
\text { Amang Lamba go lélélé ... } \\
\text { Inang Cibal go lélélé ... } \\
\text { Amang Lamba go lélélé ... } \\
\text { A é a é o ... ia ia o... } \\
\text { Bom woléng adak dé... } \\
\text { A ... é ... go lé lé lé ... } \\
\text { Amang Lamba go lélélé ... } \\
\text { Inang Cibal go lélélé ... } \\
\text { Amang Lamba go lélélé ... } \\
\text { A é a é o ... ia ia o... } \\
\text { Bom woléng adak dé... } \\
\text { Terjemahan Bebas } \\
\text { Bapa-Ibu Mertua } \\
\text { A e...la la la } \\
\text { Bapa mertua dari Lamba } \\
\text { Ibu mertua dari Cibal } \\
\text { A e a e o ... ia ia o... } \\
\text { Adat tidak berbeda } \\
\text { Bapa-Ibu Mertua } \\
\text { A e...la la la } \\
\text { Bapa mertua dari Lamba } \\
\text { Ibu mertua dari Cibal } \\
\text { Adat tidak berbeda }\end{array}$ & $\begin{array}{l}\quad \text { Naka Anak Oné Galang } \\
\text { É...o, o Mori go, yo Mori go; } \\
\text { Ho'o go Ité caid go, } \\
\text { Mori Dé wa ga oné galang go, } \\
\text { Mori go, Tabé mori Mori go, } \\
\text { tabé kraéng go, } \\
\text { ho'o cain Anak Daéng; } \\
\text { hoo kami mai kamping jari, } \\
\text { mai taung ga, } \\
\text { mai émbong Anak Daéng, } \\
\text { émbong anak Daéng, } \\
\text { suju Mori ga o suju lami taung. } \\
\text { Terjemahan Bebas } \\
\text { Pujian bagi Anak di Palungan } \\
\text { Ya Tuhan, Ya Tuhan } \\
\text { Saat ini Kau datang } \\
\text { Tuhan Allah di palungan } \\
\text { Tuhan, sembah Tuhankun } \\
\text { Anak Dewa sudah datang } \\
\text { Ini kami semuanya } \\
\text { Mari datang } \\
\text { Mari meninabobokan Anak Dewa } \\
\text { Kami semua memuji dan menyembah }\end{array}$ \\
\hline 2 & $\begin{array}{l}\quad \text { Manuk é } \\
\text { Manuk é manuk é a é a } \\
\text { Tongkéng to cama rona manuk é } \\
\text { Yo manuké ..a.. } \\
\text { tongkéng toda cama rona manuké } \\
\text { Manuk é.. manuk é a é a } \\
\text { Nggoléng nggiling oké sili } \\
\text { manuk é } \\
\text { Yo manusik é a.. } \\
\text { nggoléng nggiling oké sili } \\
\text { manuké }\end{array}$ & $\begin{array}{l}\text { Mori Gé } \\
\text { Mori gé, Mori gé a é a, } \\
\text { ho'og lami oné Rangad, Mori gé, } \\
\text { Yo Mori gé a, } \\
\text { tiba podo dami anak Mori gé. } \\
\text { Mori gé, Mori gé a é a, } \\
\text { tiba mosé, mata dami Mori gé } \\
\text { Yo Mori gé a, } \\
\text { tiba podo dami anak Mori gé. } \\
\text { Mori gé, Mori gé a é a, } \\
\text { tiba imbi bengkes dami Mori gé }\end{array}$ \\
\hline & $\begin{array}{l}\text { Terjemahan Bebas } \\
\text { Ayam Jago } \\
\text { Ayam jago, ayam jago } \\
\text { Menantang kokoh sesama jantan, oh jago } \\
\text { Ayam jago } \\
\text { Menantang kokoh sesama jantan, oh jago } \\
\text { Bergerak ke sana kemati } \\
\text { Ayam jago } \\
\text { Ayam jago } \\
\text { Bergerak ke sana kemati } \\
\text { Ayam jago }\end{array}$ & $\begin{array}{l}\text { Terjemahan Bebas } \\
\text { Tuhanku } \\
\text { Tuhaku, Tuhanku } \\
\text { Ini kami di hadapan wajahmu, Tuhan } \\
\text { Oh Tuhanku } \\
\text { Terimalah persembahan kami anakMu } \\
\text { Tuhanku, Tuhanku, }\end{array}$ \\
\hline
\end{tabular}




\begin{tabular}{|c|c|c|}
\hline No & Lagu Lokal & Lagu Gereja \\
\hline 3 & \begin{tabular}{l}
\multicolumn{1}{c}{ O... Tepong } \\
O... tepong.... a oo... tepong pong \\
wéléng nai gé \\
é... kawé laku amé go o..u...o a.. \\
kawé amé rinding mané gé a é, \\
bombang é.. bombang é kaép laku iné go.. \\
kawé iné rinding.. \\
rinding wié gé, bobang é... \\
bombang é..naég bombang, a wéong dindut... \\
dindut bon mosé gé... \\
Mori wéong wéla bombang, \\
bombang mané tana salé gé mosang \\
Ko bombang a é... \\
wéong dintu dandut bon mosé gé.
\end{tabular} & \begin{tabular}{l}
\multicolumn{1}{c}{ Mori Go } \\
Mori... go, o. Mori, nia daku é... \\
daku Mori go lawa...gé, \\
Mori nia daku Mori go, \\
Uma mina, wangka dekon gé \\
mosang Mori gé a... e \\
Wéong dindu dandut, \\
bog Morigé \\
Wéong wéla bombang, \\
Wéong wéla bombang, \\
uma mina, wangka dekon gé, mosa" \\
Mori gé a é.. \\
Wéong dindu dandut bog Morigé \\
...
\end{tabular} \\
\hline & $\begin{array}{l}\text { Terjemahan Bebas } \\
\text { Oh tepong Tepong } \\
\text { Aku kehilangan arah hidupku } \\
\text { Dimanakan kucari ayahku } \\
\text { Dimanakan kucari ibuku } \\
\text { Merekalah pelindung di sore dan malam } \\
\text { hariku } \\
\text { Hidupku tidak menentu } \\
\text { Begitu banyak tantangan di hadapanku } \\
\text { Tuhan, hidupku bagai gelombang } \\
\text { Hatiku terombang ambing } \\
\text { Hidupku makin menua } \\
\text { Hidupku makin tak tentu } \\
\text { Terombang ambing }\end{array}$ & \begin{tabular}{l} 
Terjemahan Bebas \\
\multicolumn{1}{c}{ Tuhanku } \\
Tuhanku, Tuhan dimanakah Engkau \\
Tuhanku \\
Tuhanku, dimanakah Engkau Tuhanku \\
Tuhan hidupku tak jelas \\
Ke sana kemari tak tentu \\
Tuhanku \\
Hidupku terombang ambing \\
Ke sana kemari tak tentu \\
Aku terombang-ambing \\
Ke sana kemari tak tentu
\end{tabular} \\
\hline 4 & $\begin{array}{l}\text { O Ende } \\
\text { O endé nia hau ga } \\
\text { Coo tara pucang one wejang } \\
\text { Legong oné leso } \\
\text { Dindur dandur mosé dami } \\
\text { O endé nia hau ga } \\
\text { Coo tara pencang oné wejang } \\
\text { Legong oné léso } \\
\text { Dindur dandur mosé dami }\end{array}$ & $\begin{array}{l}\text { Jimbal de Morin } \\
\text { Yo..o.. jimbal de Morin, } \\
\text { Ite koso ndékok de lino, Baéng koé ami } \\
\text { Jimbal de Morin } \\
\text { Yo..o.. jimbal de Morin, } \\
\text { Ite koso ndékok de lino, Baéng koé ami } \\
\text { Jimbal de Morin } \\
\text { Yo..o.. jimbal de Morin, } \\
\text { Ite koso ndékok de lino, Hambor koé ami }\end{array}$ \\
\hline & $\begin{array}{l}\text { Terjemahan Bebas } \\
\quad \text { O Ibu } \\
\text { O ibu, dimanakah engkau } \\
\text { Mengapa kau tinggalkan aku sendirian } \\
\text { Mengapa engkau melepaskan aku di teriknya } \\
\text { siang } \\
\text { Hidupku tak menentu arah } \\
\text { Dimanakah engkau ibuku } \\
\text { Mengapa engkau melepaskan aku } \\
\text { Hidupku tak menentu arah }\end{array}$ & \begin{tabular}{l} 
Terjemahan Bebas \\
\multicolumn{1}{c}{ Anak Domba Allah } \\
Anak Domba Allah yang mengapus dosa- \\
dosa dunia \\
Kasihanilah kami \\
Anak Domba Allah yang mengapus dosa- \\
dosa dunia \\
Kasihanilah kami \\
Anak Domba Allah yang mengapus dosa- \\
dosa dunia \\
Berilah kami damai
\end{tabular} \\
\hline
\end{tabular}




\begin{tabular}{|c|c|c|}
\hline No & Lagu Lokal & Lagu Gereja \\
\hline 5 & $\begin{array}{l}\text { Sanda Kukur } \\
\text { Kukur kukur élor ga } \\
\text { Kukur kukur élor ga } \\
\text { Mbau a é o } \\
\text { Le mbau lémo } \\
\text { Le mbau lémo gé a } \\
\text { Kukur é Ili mbau } \\
\text { Kukur é Ili mbau } \\
\text { Ili mbau kukur }\end{array}$ & $\begin{array}{l}\quad \text { Yesus Kristus Mori ge } \\
\text { Yesus Kristus Mori gé } \\
\text { Yesus Kristus Mori gé } \\
\text { Morin o wakarn gé } \\
\text { Landing go a momang wakar gé a } \\
\text { Landing go a momang wakr géa } \\
\text { Mori Yesus mata oné panggol } \\
\text { Mori Yesus mata one panggol } \\
\text { Panggol mendo yo Mori gé }\end{array}$ \\
\hline & \begin{tabular}{l} 
Terjemahan Bebas \\
\multicolumn{1}{c}{ Sanda Kukur } \\
Burung tekukur terbang \\
Burung tekukur terbang \\
Mencari tempat teduh \\
Di naungan pohon limau \\
Di bawah naungan pohon limau \\
Burung tekukur mencari naungan \\
Burung tekukur mencari naungan \\
Mencari naungan burung tekukur
\end{tabular} & $\begin{array}{l}\frac{\text { Terjemahan Bebas }}{\text { Yesus Kristus Tuhanku }} \\
\text { Yesus Kristus Tuhanku } \\
\text { Yesus Kristus Tuhanku } \\
\text { Tuhan jiwaku } \\
\text { Karena sayang akan jiwaku } \\
\text { Karena sayang jiwaku } \\
\text { Tuhan Yesus rela memanggul salib } \\
\text { Tuhan Yesus rela memanggung salib } \\
\text { Salib berat ya Tuhanku }\end{array}$ \\
\hline 6 & $\begin{array}{l}\quad \text { Sanda Congka Kolong } \\
\text { E lurang tali wua } \\
\text { Jangka tali manga } \\
\text { Rencak ata mengga } \\
\text { To'o ludung kole } \\
\text { Wakak betong ara } \\
\text { Manga waken nipu tae } \\
\text { Muntung gurung pu'u } \\
\text { Manga kungkut ludung curup }\end{array}$ & $\begin{array}{l}\quad \text { E Nai Nggeluk Wa'u } \\
\text { E Nai Nggeluk wa'u eta mai } \\
\text { Wa'u ge one ami ga } \\
\text { O ae a e hendeng Mori mese } \\
\text { Mbau taung ge } \\
\text { O o mai Mori yo } \\
\text { O eo a o a e e a } \\
\text { E hendeng Mori mese } \\
\text { Mbau taung ge }\end{array}$ \\
\hline & $\begin{array}{l}\text { Terjemahan Bebas } \\
\quad \text { Tarian Congka Kolong } \\
\text { Tali rotan } \\
\text { Tali lama menua } \\
\text { Yang baik sudah membusuk } \\
\text { Ditumbuhi jamur } \\
\text { Bambu menua } \\
\text { Ada maksud semuanya } \\
\text { Terbakar bambu hutan } \\
\text { Ada makna dari segala kehilangan }\end{array}$ & $\begin{array}{l}\text { Terjemahan Bebas } \\
\quad \text { Turunlah Roh Kudus } \\
\text { Oh Roh Kudus turunlah dari atas } \\
\text { Turun ke atas kami } \\
\text { Bimbinglah hidup kami } \\
\text { Naungilah hidup kami } \\
\text { Datanglah Tuhan } \\
\text { Bimbinglah hidup kami } \\
\text { Naungilah hidup kami }\end{array}$ \\
\hline
\end{tabular}

Sampai dengan tahun 1970an, kehadiran Déré Serani menjadi fenomena penting dalam perkembangan Gereja Katolik Manggarai. Liturgi Latin-Romawi yang kaku dan tidak menarik diubah menjadi liturgi berwarna dan nuansa lokal. Namun tentu saja, menurut kesaksian beberapa orang tua, awalnya orang tua dan mereka sendiri bercerita bahwa terasa ada yang aneh dari fenomena ini. Perbedaan

teologi, konteks, waktu, isi, dan makna lagu adat menjadi lagu misa adalah hal yang membingungkan dan ironis. Namun, tak bisa dipungkiri Déré Serani menjadi ikon bagaimana Gereja berwajah barat masuk di dalam kebudayaan lokal. Déré Serani adalah simbol gereja yang masuk di dalam budaya lokal. Déré Serani menjadi pembentuk identitas yang kuat antara kekatolikan dan kemanggaraian di 
wilayah ini. Dengan Déré Serani budaya lokal masuk ke dalam ruang sakral baru, ke dalam wilayah agama/Gereja Katolik.

\section{Ironi Kemunduran Post Vatikan II}

Konsili Vatikan II yang berlangsung 1962-1965 di Vatikan merupakan babak baru sejarah perkembangan agama Katolik mondial. Perubahan teologi, liturgi dan hukum Gereja yang fundamental yang dibawa konsili menjadi arah baru Gereja Katolik. Salah satu dokumen penting yang dihasilkan konsili ini adalah Sacrosanctum Concilium (1963) yaitu Konsititusi tentang Liturgi Suci. Dokumen ini merekomendasikan perubahan liturgi Gereja, dimana Gereja menginginkan agar umat terlibat lebih aktif di dalam liturgi dan Gereja sendiri diberanikan untuk menerjemahkan liturgi Latin ke dalam budaya dan bahasa lokal. Teologi Vatikan II juga menjadi sangat ramah dengan dunia dan kebudayaan lokal.

Perubahan ini seharusnya menjadi angin segar bagi gereja-gereja lokal di seluruh dunia. Bagi orang Manggarai, tata liturgi yang inkulturatif sudah mulai dipraktikkan dan dikembangkan sejak beberapa dekade sebelum konsili berbicara mengenai hal ini. Semuanya karena jasa Uskup Ruteng (Manggarai), Willem van Bekkum. Tahun 1972, uskup ini "dipaksa" mengundurkan diri (Jehandut, 2012: viiii). Seorang uskup lokal Manggarai diangkat untuk menggantikan beliau. Uskupuskup penggantinya hingga dewasa ini juga merupakan putra lokal Manggarai. Ironisnya, justru ketika Konsili Vatikan II mengemakan perubahan liturgi yang lebih ramah terhadap budaya lokal dan ketika Gereja Manggarai dipimpin oleh putra daerah sendiri, usaha untuk menciptakan dan menambah koleksi lagu-lagu adat di dalam Gereja justru mengalami kemunduran.

Periode tahun 1980an-2010 ada dekade melemahnya penggunaan Déré Serani dan lagu-lagu adat lainnya di dalam Gereja Katolik Manggarai pada umumnya. Pengembangan baru Déré Serani telah selesai dengan berakhirnya jabatan Uskup Willem van Bekkum, misionaris asal Belanda. Ini sebuah ironis karena sebenarnya Konsili Vatikan II baru saja membuka lembaran barunya. Hal ini terjadi karena tokoh dan agen yang peduli pada inkulturasi dan kebudayaan lokal, dalam hal ini Willem van Bekkum telah dihentikan langkahnya.

Selain karena faktor ketiadaan penggerak inkulturasi, ada beberapa alasan lain melemahnya usaha inkulturasi di Manggarai. Pertama, paska Konsili Vatikan II, Gereja Indonesia mengambil peran untuk menerjemahkan liturgi Latin ke dalam bahasa Indonesia dan demikian juga lagu dan musiknya. Pada Kongres Musik Liturgi 1980 di Jakarta disepakati terbitnya buku lagu "Madah Bakti" dalam bahasa Indonesia. Lagu-lagu ini berasal dari berbagai kebudayaan, tetapi tidak ada dari Manggarai. Meskipun demikian, Madah Bakti mulai "dipaksakan" masuk ke dalam Gereja Manggarai. Penggunaan ini menyebabkan Déré Serani tersingkir. Sejalan dengan ini, sejak tahun 1980an, alat musik seperti gitar, keyboard, organ semakin populer penggunaannya di kalangan Gereja. Hal ini semakin meminggirkan Déré Serani.

Kedua, melemahnya penggunaan dan penciptaan lagu baru juga karena di masa ini, banyak orang berpendidikan beranggapan bahwa hal-hal yang berkaitan dengan kampung, adat, dan bahasa Manggarai adalah hal yang rendah dan kampungan. Orang merasa lebih keren kalau berbahasa Indonesia. Pemikiran seperti ini juga karena pengaruh pendidikan yang semakin meluas di Manggarai, yang juga sejalan dengan masa Orde Baru yang cenderung meremehkan, mendiskriminasi, dan meminggirkan budaya lokal dan peran-peran adat di dalam diskusrus politik Indonesia.

Ketiga, ini adalah era dimana peran misionaris dan pastor asing melemah karena sudah tergantikan oleh imam-imam lokal. Imam lokal, sejak kecil telah dididik di asrama dan luar Manggarai, terpisah dari kebudayaan mereka, maka kecintaan dan pengetahuan terhadap budaya melemah. Ditambah lagi banyak di antara mereka tidak berminat dan tidak punya pada studi antroplogis/budaya, tetapi lebih pada pastoral rohani. Tidak heran, ketika mereka bertugas, mereka kurang memiliki perhatian terhadap aspek budaya 
lokal di dalam pelayanan pastoral. Beberapa imam yang mengikuti aliran karismatis, malahan cenderung menghilangkan aspek budaya lokal di dalam kehidupan umat karena dianggap menghalangi keselamatan.

Pada tahun 2012, Gereja Manggarai merayakan 100 tahun Gereja Katolik di Manggarai. Perayaan seabad Gereja ini terjadi pada era reformasi, dimana ada arus kebangkitan budaya di level nasional. Maka, pertanyaan untuk menggali kembali kemanggaraian menguat, termasuk menghidupkan kembali Déré Serani. Keuskupan Ruteng mencanangkan agar setiap minggu ke-3 menjadi minggu inkulturasi, yaitu minggu di mana misa dan lagu-lagu dinyanyikan dalam bahasa Manggarai. Akan tetapi, sejauh pengamatan peneliti, ini sifatnya hangathangat tai ayam dan lebih berdasarkan selera saja. Bukan sebuah kebangkitan yang sejati. Beberapa tokoh imam dan awam menawarkan beberapa bentuk inkultuasi namun sifatnya sporadis. Secara umum, Gereja hanya memakai saja peninggalan lama. Namun, bagaimanapun, perjalanan seabad Gereja telah membentuk identitas Katolik-Manggarai atau ManggaraiKatolik yang sangat kental.

\section{SIMPULAN}

\section{Perjumpaan Agama-Budaya yang Dinamis}

Penelitian ini memperlihatkan seni telah menjadi jalan perjumpaan antara dua kebudayaan dan keyakinan yang berbeda: antara kebudayaan Manggarai dan tradisi Gereja Katolik. Gereja Katolik yang dibawa para misionaris barat tidak pernah hadir pada suatu ruang kosong. Usaha untuk mendominasi dengan hanya menawarkan seni dan liturgi luar tidak akan pernah berhasil mengambil hati masyarakat. Pemaksaan nilai, keyakinan dan seni eksternal hanya akan berakibat keterasingan. Sebaliknya berdialog dan berdialektika dengan kebudayaan setempat akan menjadi satu keuntungan bagi Gereja Katolik. Sejarah memperlihatkan, kekatolikan diterima dengan cepat dan perkembangannya sangat pesat justru karena ia berani mengambil risiko untuk tidak melulu menggunakan seni dan liturginya sendiri saja, tetapi bersedia masuk di dalam budaya dan mengakomodasi kekayaan lokal. Demikian pula, masyarakat Manggarai bukanlah agen pasif. Seni, seniman dan masyarakat lokal memperlihatkan peran aktif dalam memberi warna bagi Gereja dan iman Katolik.

Neibuhr (2001) dan Bevans (2005, 2006) melakukan studi mengenai perjumpaan antara agama Kristiani dan kebudayaan lokal. Di dalam model yang mereka kembangkan, relasi agama dengan budaya dapat terjadi dalam beberapa fase atau model. Ada perjumpaan yang menghasilkan hubungan kontradiksi dimana nilai-nilai yang dianut kedua belah pihak bertentangan satu sama lain dan tak ada jalan untuk memperjumpakan dan mendialogkan keduanya. Orang hanya bisa memilih menerima yang satu dengan menolak yang lain. Menerima keduanya adalah mustahil. Ada model perjumpaan yang sifatnya paralel. Di sini, dua hal dianggap sama baik di dalam dirinya sendiri namun tidak urgen untuk disatukan. Keduanya tetap berada pada pendiriannya sendiri-sendiri tanpa saling menggangu. Pada level ini, hubungan sebenarnya tidak terjalin karena tidak ada penghubung, tidak ada relasi dan komunikasi satu sama lain. Model yang lain adalah hubungan saling memperkaya. Di dalam model ini ada dialog yang saling menguntungkan antara agama dan budaya. Olehnya dialog bisa terjadi dan saling memperkaya karena substansi nilai, makna dan kebenaran dapat dibagi dan diterima satu sama lain.

Model-model ini secara umum juga menjadi bagian dari dinamika perjumpaan seni lokal dan gereja berjumpa di Manggarai. tetapi, penelitian ini menemukan bahwa perjumpaan yang mutualis adalah yang paling dominan terjadi dan sekaligus menjadi fundamen penting pembentukan identitas budaya dan agama, Manggarai, dan Katolik yang bagaikan satu koin dengan dua sisi tak terpisahkan.

\section{DAFTAR PUSTAKA}

Allerton, C. 2009. Static Crosses and Working Spirits: Syncretism and Agricultural 
Animism in Catholic West Flores. Anthropological Forum 19 (3): 271-287.

Bevans, S.B. 2005. Models of Contextual Theology (Revised and Expanded Edition), New York: Orbis Books.

Bevans, S.B., Schroeder, and Roger P. 2006. Constants in Context: A Theology of Mission for Today, Maryknoll, New York: Orbis Books.

Christantyawati, N. Walensa, L., Juraman, S. R, Budaya Unu Tanah dan Budaya Lio: Menyoal Narasi Mitos Tanah, Hermenuetika Alam, dan Komunikasi Lintas Generasi, Kawistara 8 (1): 61-110. https:// doi. org/10.22146/kawistara.29751

DOI: https://doi.org/10.22146/ jh.v30i3.29216

Erb, M.,dan F. Widyawati. 2018. Missionaries and Mining: Conflicts over Development in Eastern Indonesia. Dalam The Mission of Development, Religion and Recho-Politics in Asia. Editors C. Scheer, P. Fountain, \& M. R. Feener. Netherland and Boston: Brill. DOI: https://doi. org/10.1163/9789004363106_005

Erb, M., 2007. Adat Revivalism in Western Flores: Culture, Religion, and Land. Dalam The Revival of Tradition in Indonesian Politics: the Deployment of Adat from Colonialism to Indigenism. Editor: Davidson, S. James and Henley, David. London \& New York: Routledge.

Harnis, D. 2006. Bridges to the Ancestors: Music, Myth and Cultural Politics at an Indonesian Festival, University of Hawaii Press.

Harnish, D. dan A. Rasmussen (Ed). 2012. Divine Inspirations: Music and Islam in Indonesia, New York: Oxford University Press.

Harnish, D. 2014. Balinese and Sasak Relijious Trajectories in Lombok. Interactions, Tensions and Performing Arts at the Lingsar Temple Festival dalam Between Harmony and Discimination: Negotiating Religious Identities within Majority-Minority Relationships in Bali and Lombok, editor. Briggita Hauser Schaublin dan David Harnis, Leiden/ Boston: Brill: 61-83. DOI: https:/ / doi. org/004_9789004271494/10.1163.

Jehandut, B. 2012. Uskup Wihelmus van Bekkum \& Dere Serani. Pengintegrasian Unsur Religiousitas Asli Masyarakat Manggarai ke dalam Liturgi, Nera Pustaka: Jakarta

Lon, Y dan Widyawati, F. 2019. “Pork in Communal Dining: MuslimCatholic Relations in Flores, Eastern Indonesia." Studi Islamika volume 26 number 33, (2019): 445-474. DOI: https://doi.org/10.36712/sdi. v26i3.9917

Messner, G.K. 1981. Two-part vocal style on Baluan Island, Manus Province, Papua, New Guine. Ethnomusicilogy. 25 (3): 433-446.

Molnar, A.K. 1997. Christianity and Traditional Religion among the Hoga Sara of West-Central Flores. Anthropos, 4(6): 393- 408.

Niebuhr, H.R. 2001. Christ and Culture, San Francisco: Harper \& Row.

Poplawska, M. 2011. Christianity and Inculturated Music in Indonesia. Southeast Review of Asian Studies. 33: 186-198.

Prier, K.E. 2007. Perjalanan Musik Gereja Katolik Indonesia Tahun 1957-2007.Yogyakarta: Pusat Musik Liturgi.

Rahim, A., W.N. Chistianto. 2019. Negosiasi atas Adat dalam Sistem Pelaksanaan Tradisi Nyongkolan Sasak Lombok. Kawistara 9 (1): 28-44. https://doi. org/10.22146/kawistara.36125

Rappoport, D. 2015. Music as Evidence of Settlement: the Case of Diphonic singing in Eastern Indonesia (Eastern 
Flores, Eastern Timor), Language Documentation and Cultural Practices in the Austronesian World. 4: 135-148.

Romano, F. J., 2014. Liturgy and Society in Easly Mediaeval Rome. Chucrh, Faith and Culture dalam The Medieval West Series, Farhmam-Burlington, VT: Ashgate Publishing.

Setyari, N.P.W., Badensa I.K.G. dan Saskara. I.A. 2019. Proporsi Adat Budaya di Bali dan Pengaruhnya terhadap Kesejahteraan Masyarakat Lokal. Kawistara 9 (1): 91-106. https:// doi. org/10.22146/kawistara.36526

Steenbrink, K. 2007. Catholics in Indonesia. 1903-1942: A Documented History, vol. 2, Leiden: KITLV Press.

Toda, D.N., 1999. Manggarai: Mencari Pencerahan Historiografi, Ende: Nusa Indah.

Verheijen, J. 1967 Kamus Manggarai I: Manggarai-Indonesia, Kooninklijk Instituute vor taal Land- en Volkenkunde, EsgavenhageMartinus Nijhoof.

Verheijen, J. 1970. Kamus Manggarai, 2, s'Gravenhage: Nijhoff.

Widyawati, F. 2012. Kolonialisme, Islamisasi dan Masuknya Agama Katolik di Manggarai. Missio 4 (1): 47-58
Widyawati, F. 2018. Catholics in Manggarai, Eastern Indonesia, Geneva: Globethics. net

Widyawati,F.dan Yohanes, S.L. 2019. Mission and Development in Manggarai, Flores Eastern Indonesia. Paramita 29 (2): 178-189.

Widyawati, F. dan Purwatma, M. 2013. The Development of Catholicism in Flores, Eastern Indonesia: Manggarai Identity, Religion and Politics, Dissertation, UGM Yogyakarta

Yampolsky, P. 2015. Is Eastern Insulinda a Distinct Musical Area? Archipel 90: 153-187

\section{Buku Lagu:}

Dere Serani.1973. Cetakan III, Ende: Nusa Indah.

Dere Serani. 2008. Cetakan XIII, Ende: Nusa Indah.

\section{Interviews:}

- Mr. Stanis Tatul (72 years old)

- Mr. Nobert (90 years old)

- Mr. Albert (74 years old)

- Mr. Anton (65 years old)

- Mr. Lamber (73 years old)

- Mr. David (68 years old)

- Mr. Thomas (65 years old) 